\title{
Reduction of Eddy Current Losses in Fractional-Slot Concentrated-Winding Synchronous PM motors
}

\author{
Sisuda Chaithongsuk ${ }^{1}$, Noureddine Takorabet ${ }^{2}$, Sangkla Kreuawan ${ }^{3}$ \\ ${ }^{1}$ Rajamangala University of Technology Suvarnabhumi, Nonthaburi, 11000, Thailand \\ ${ }^{3}$ Université de Lorraine - GREEN, 54516, Vandoeuvre lès Nancy, France \\ ${ }^{3}$ National Electronics and Computer Technology Center - MDD-AAERU, Pathum Thani, 12120, Thailand \\ noureddine.takorabet@univ-lorraine.fr
}

\begin{abstract}
This paper focuses on the reduction of eddy-current losses in Fractional slot inset PM motors. The flux paths of the armature reaction is modified based on pulse width modulation technique. Undesirable harmonic contents of the air-gap flux density can be reduced. This improves back EMF waveform quality and reduces the amplitude of eddy currents in the solid rotor and the magnets. Rotor losses are strongly reduced by this technique.

Index Terms - Eddy-currents losses, PM motor, Fractional slot winding.
\end{abstract}

\section{INTRODUCTION}

$\mathrm{F}$ RACTIONAL-SLOT Permanent Magnet motors are characterized by high quality of the back EMF waveforms with the use of some slot-pole number combinations. They can provide many opportunities in different applications [1] [2]. Torque pulsation can be reduced by designing stator slot shape, skewing stator or magnets, which has also an impact on cogging torque. Another method consists in reducing backEMF harmonics by modifying flux path. These machines have the drawback of a high level of eddy currents in the rotor which may have three origins :

- The high frequency losses due the carrier harmonics of the stator current

- The slotting losses in the PMs due to the permeance variation even if the stator is not supplied

- The armature reaction due to the current MMF harmonics.

The level of the losses depends on the topology of the machine and the quality of inverter [3] [4]. Generally, the surface mounted PMs are subject to high level of losses if they are not protected by a conducting ring. Unlike, the inset PMs are protected by the rotor lamination and the level of the losses is generally low. For economic reasons, the rotor can be made of solid iron so eddy currents are free to flow in the rotor and the losses are increases. In this case, the temperature of the rotor may increase and the magnets can be warmed by thermal conduction of the losses. Therefore, it is necessary to reduce the losses in the rotor even if the eddy currents are located in the solid iron. In such situation, the rotor losses are mainly due to the armature reaction, especially the low order harmonics of the electromagnetic field due to the stator currents. Fore surface PM motors, high frequency harmonics are filtered by the air-gap and/or by a conducting ring for surface PM motors. Many papers have been published to compute such losses through different means [5] [6].

This paper deals with the reduction of low order harmonics of the armature field by changing the shape of the rotor surface. The reduction of rotor losses in PM Motors has been a wide field of investigations these last decades [7]. The use of
PWM technique presented in a previous paper [8] allows reducing some harmonics of the air-gap permeance. In this case, some undesirable harmonics of the armature field are strongly reduced. The grooving of the rotor surface creates current barriers for the eddy currents on the rotor surface. The optimization of the number of the grooves and their position is essential to reduce the eddy current without changing the output performances (EMF and Torque). These points are examined and discussed in this paper

\section{MODELING OF THE ROTOR LOSSES}

The case of sinusoidal currents is considered in this paper. The stator currents can be modeled by an equivalent current sheet $J_{s}(\theta, t)$ on the inner surface of the stator. The current sheet is expressed in terms of space harmonics depending on the winding arrangement.

$$
J_{S}(\theta, t)=\frac{\sqrt{2} N I}{\pi R} \mathcal{R} e \sum_{h} K_{w h} \exp (i \omega t-h p \theta)
$$

where $\omega$ is the stator current frequency, $N$ is the number of turns. $K_{w h}$ denotes the winding factors for the $h_{t h}$ harmonic that can be calculated by classical formula established many decades ago [9]. Many new contribution have been presented for the calculation and the comparison of the winding factors for many topologies including different effects [10].

It is well known the harmonics of the armature reaction creates traveling waves (forward and backward) which are the source of eddy currents in the rotor of synchronous machines. Fractional Slot PM machines have the drawback that the amplitude of this harmonics is too high compared to overlapping sinusoidal windings. This is well quantified by the winding factors. For 3-phase machines the harmonics of rank $(6 k \pm 1)$ are the sources of eddy current of frequency $(6 k \omega)$.

The eddy currents flow on rotor surface and penetrate through the rotor according to the skin depth which depends on the frequency and the material properties. The modification of the topology of the surface can be a good solution to create current barriers for these eddy currents.

The modeling of eddy currents in the rotor can be performed by Time Stepping FEM (TSFEM) taking into account saturation, exact currents waveforms and machine topology. This method is CPU time consuming and needs a 
large memory space. In addition, it cannot separate the different contribution of the winding harmonics to the rotor losses. The losses are calculated with a global way.

The use Time Harmonic FEM (THFEM) models is useful for save CPU tame and separate the physical phenomena. The superposition principle can be applied for this purpose. The global saturation can be taken into account by modifying the permeability of the ferromagnetic parts so that the saturation level is equivalent to the real operation of the machine.

Assuming all these considerations, the model can be based on the superposition of the different harmonics of the equivalent current sheet on the inner surface of the stator as illustrated on Fig. 1

For each considered space harmonic of rank $h$ the following problem can be solved by THFEM:

$$
\begin{aligned}
& \nabla^{2} A_{h}=0 \quad \text { in the stator \& air-gap } \\
& \nabla \cdot v \nabla A_{h}=j \sigma \omega(h-1) A_{h} \quad \text { in the rotor } \\
& J\left(R_{S}, \theta\right)=\sqrt{2} \frac{N I}{\pi R_{S}} K_{w h} \exp (h p \theta) \text { on } \Gamma
\end{aligned}
$$

where $A_{h}$ is the complex representation of the $h^{\text {th }}$ space harmonic of the magnetic vector potential, $v, \sigma$ are the magnetic reluctivity and the electric conductivity. In this problem, the harmonic rank $h$ is considered with its algebraic value of the form $1 \pm 6 k$ so that the nature of the travelling wave (backward, forward) are taken into account. the considered harmonics are limited to the 6 first undesirable harmonics of rank $(-5,7,-11,13,-17,19, \ldots)$ and their corresponding frequencies are of the form $6 k \omega, k=1,2,3$. The higher order harmonics are strongly filtered by the air-gap and their contribution in too weak. On the other hand, the technique proposed for the reduction of eddy currents losses does not affect them. This will be discussed in the section IV dealing with the results.

The computation of the eddy current in 2D model has to take care that the "go" and "return" currents are in the same massive region. The grooves and PMs are creating isolated region where the constraint $\nabla . J=0$ has to be verified in the FEM model. Therefore:

$$
\nabla . J=0 \text { soit } \iint_{\text {magnet }} j_{z}(x, y) d x d y=0
$$

The eddy current losses are the calculated using classical Ohm law:

$$
P_{e d d y}=\iint \sigma^{-1} J_{z}^{2}(x, y) d x d y
$$

\section{REDUCTION OF THE ROTOR LOSSES BY MEAN OF PWM DESIGN TECHNIQUE}

The harmonics amplitudes of the equivalent current sheet are the source of the harmonics of the air-gap flux density. They depend on the winding factors and the rotor pole number. However, the harmonics of magnetic flux density in the air-gap depend also on the air-gap topology that they cross. So the air-gap permeance is an important parameter to considered for the reduction of rotor eddy currents. The topology of the air-gap can be modified so that the permeance of the fundamental is unchanged and the permeance of the of the high order harmonics is strongly reduced. Thus the
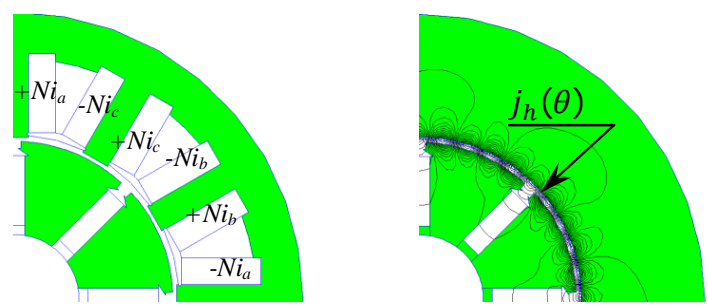

Fig. 1. Principle of equivalence between ampere-turns and equivalent current density sheet.

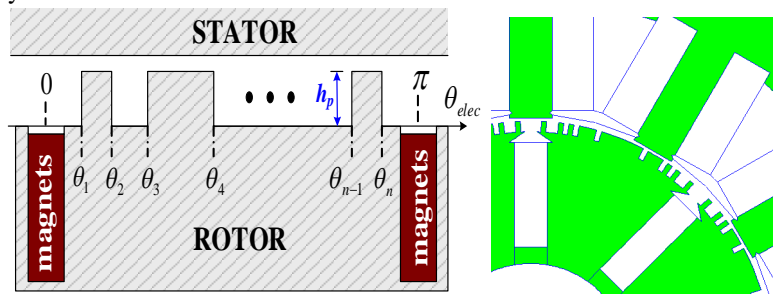

(a) Idealized shape

(b) Real shape

Fig. 2. Principle of grooved rotor with inset Permanent Magnets.

fundamental (first harmonic) of the flux density can cross the air-gap easily whereas, the other harmonics are filtered. The main effect of such situation is the reduction of the flux and EMF harmonics. This principle has been used in previous [8] for the reduction of EMF harmonics and torque ripples of different topologies of PM machines. In the case of Fractional slot Inset PM motor with solid iron rotors this principle can have a great effect on the eddy currents due to the armature reaction.

Consider an idealized representation of the one pole of the rotor Fig. 2.a. The surface of the solid rotor is grooved with a given number of groove over one period. These grooves are characterized by the angles $\theta_{1}, \theta_{2}, \theta_{3}, \ldots \theta_{n}$ and the thickness $h_{p}$. An example of the real shape of the rotor is given in Fig. 2.b. The positions and sizes of these grooves can be optimized so that a given set of harmonics can be strongly reduced. This can be represented by the reduction of the corresponding permeances. For a given space harmonic, the permeance can be calculated by :

$$
P_{h}=\mu_{0} \int_{2 \pi / h} d s / g(\theta)
$$

where $d s=L_{z} R d \theta$ is the surface element of integration depending on the stack length $L_{z}$ and the radius $R$ of the rotor. $g(\theta)$ is the air-gap length which depends on the position of the grooves and their thickness. It can be idealized with the following formulation :

$$
g(\theta)= \begin{cases}g+h_{p} & \text { in the groove } \\ g & \text { elsewhere }\end{cases}
$$

The permeance $P_{h}$ corresponding to a given harmonic can be expressed as a function of the angles $\theta_{1}, \theta_{2}, \theta_{3}, \ldots \theta_{n}$ which are gathered in the variable $x$.

$$
x=\left[\theta_{1}, \theta_{2}, \theta_{3}, \cdots, \theta_{n}\right]^{T}
$$

For 3-phase machines, PWM technique presented in [8] can be used to reduce the permeance of the high order harmonics of rank $6 k \pm 1$ with the constraint that the permeance $P_{1}$ corresponding to the fundamental is slightly constant. This obtained air-gap topology operates such as a filter for the armature field in the air-gap. The problem can be written in 
the following form:

$$
\begin{aligned}
& F(x)=\sum_{k=1}^{K \max } P_{6 k \pm 1}^{2}(x) \\
& \quad \min _{x \in R^{n}} F(x) \\
& \text { subject to: : } g(x)=P_{1}(x)-P_{0}=0
\end{aligned}
$$

where $P_{0}$ is the required value of the permeance for the fundamental. The angles $\theta_{i}$ are defined between 0 and $\pi$ II. Therefore, an additional constraint should be added to the optimization problem as follows:

$$
0<\theta_{1}<\theta_{2}<\theta_{3}<\cdots \theta_{n-1}<\theta_{n}<\pi
$$

Then the main problem consists to find the angles $\theta_{1}, \theta_{2}, \theta_{3} \cdots, \theta_{n}$ which minimize the function $F(x)$ subject to the different constraints. For this purpose, any optimisation method can be applied. he function "fmincon" of Matlab Optimization Tool box can be used as well as any other optimization software. By this way, the shape of the rotor surface can be designed in order to eliminate a set of space harmonics.

\section{APPLICATION TO FRACTIONAL SLOT INSET PM MOTOR}

The case of a 12-slot, 8-pole Interior PM motor is considered. The other parameters of the motor are given in Tab. I. The surface of the rotor can be smooth (Fig.3.a) or grooved with equal and equidistant grooves (Fig.3.b) or using PWM technique presented above (Fig.3.c). The shape given in Fig.3.b is obtained by performing 8 equidistant grooves on each pole surface of equal width of 5 electrical degrees. The shape given in Fig.3.c is calculated by solving the problem (9)-(10)-(11) with only 5th and 7th harmonics of flux density to be reduced ( $h=-5$ and $h=7$ ). Different other shapes can be obtained according to the set of undesirable harmonics included in the optimization problem. The stator is supposed to be supplied by an inverter vector controlled, providing sine wave currents in the $q$-direction.

\section{A - Steady state Performances calculation:}

The back EMFs of such machine contains some harmonics due to the rotor topology. It is easy to reduce this content by means of some structural design. The use of PWM technique grooves on the surface rotor allows reducing a given set of harmonics and consequently the torque ripples. Figure 3 shows the back EMF and torque waveforms obtained by the three rotor topologies. It can be clearly seen that the PWM rotor allows reducing the 6th harmonic of the torque waveforms.

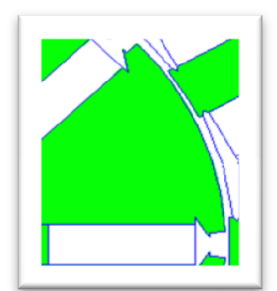

(a) Smooth

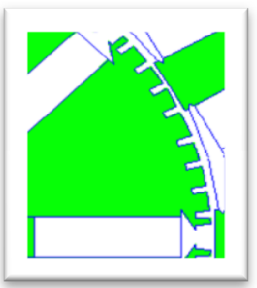

(b) Equidistant

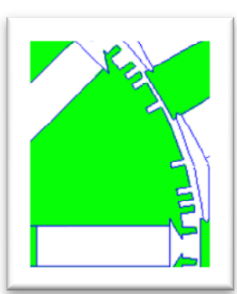

(c) PWM
TABLE I

PARAMETERS OF STUDIED SOLID ROTOR INDUCTION MOTOR

\begin{tabular}{lcc}
\hline \hline Parameter & Symbol & Value and unit \\
\hline Output Power & $P$ & $5 \mathrm{~kW}$ \\
Rms phase current & $I_{m}$ & $8 \mathrm{~A}$ \\
Rms phase voltage & $V_{m}$ & $230 \mathrm{~V}$ \\
Frequency & $f$ & $50 \mathrm{~Hz}$ \\
Stack length & $L_{u}$ & $200 \mathrm{~mm}$ \\
External Diameter of the stator & $D_{e x t}$ & $160 \mathrm{~mm}$ \\
\hline \hline
\end{tabular}

\section{$B$ - Analysis of the rotor eddy current and losses}

The stator equivalent current sheet on the stator inner surface is of the form given in (1). The corresponding winding factors are calculated by analytical formula. The calculation of eddy currents in the rotor due to the armature reaction is performed for each space harmonic separately. Therefore the problem (2), (3), (4) is solved for the set of harmonics $(h=-5,7,-11,13,-17,19)$ and the eddy current losses are computed by (6). Finally, the whole losses are calculated for the three topologies.

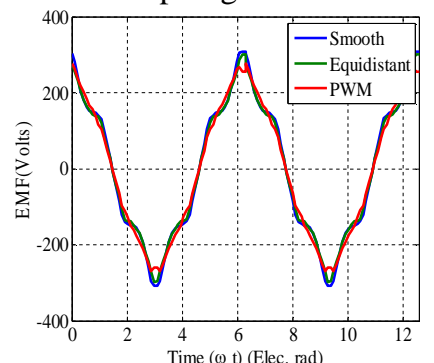

(a) Back EMF

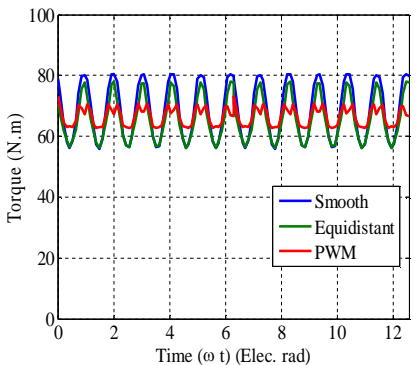

(b) Torque
Fig. 4. Steady state performances of the 3 topologies.

A special care is taken to the mesh size on the top of the rotor in order to take into account the decrease of the skin depth due the increase of the frequency. On the other hand, to take into account the presence of the grooves the principle of conservation of the current density given by (5) is applied to the top side of the rotor (teeth). As an illustration, the amplitude of eddy current density is shown on Fig. 4 for the 3 rotors. It can be seen that the level of eddy current is strongly reduced with both equidistant and PWM grooving of the rotor surface. The grooves "cut" the path of the eddy currents operating such as a current barrier.

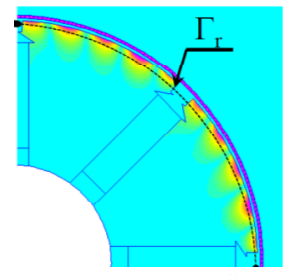

(a) Smooth

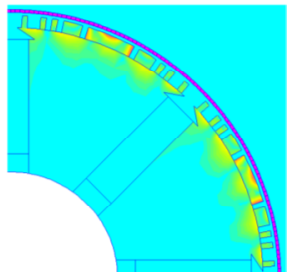

(c) PWM

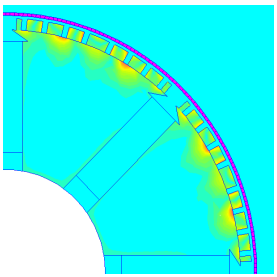

(b) Equidistant
Fig. 5. Shape Eddy current isolavues in the rotor due the 5th harmonic. 

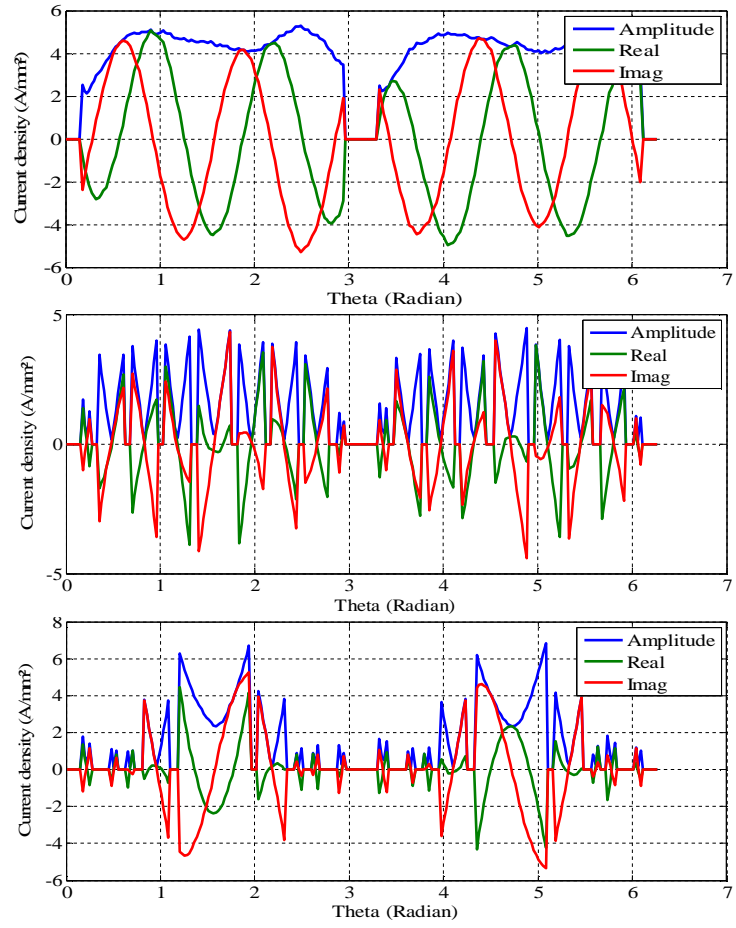

Fig. 6. Current density waveforms over one period along the path $\Gamma$.

The path $\Gamma$ passing on the top of the rotor over one mechanical period is considered (Fig.4.a). Figure 6 shows the eddy current distribution on $\Gamma$ due to the 5 th harmonic of the armature reaction (real - imaginary parts and amplitudes). In the case of the smooth rotor, the eddy currents are free to flow through the rotor surface of each pole with the corresponding skin depth (Fig.5.a). The grooves on the rotor surface are equivalent to current barriers to the eddy currents if the distance between two adjacent grooves is smaller than the pole pitch of a given harmonic. It is clearly seen in Fig. 5.b and Fig.5.c that the current density waveforms are strongly disturbed by this grooving. Fig.7 shows the losses in the permanent magnet and in the rotor for each considered harmonic. The relative reduction of the eddy current losses is significant for the 5th and 7 th harmonics. The relative reduction of the eddy current losses is less significant for high order harmonics. Fortunately, these losses are too weak weak. Consequently the whole rotor losses on the rotor surface are reduced.

On the other hand; the space harmonics of the flux density in the air-gap is reduced and the top side of the magnets are protected by this technique against these harmonics. The eddy current losses in PMs are also strongly reduced even if they are too weak compared to the losses in the solid rotor.
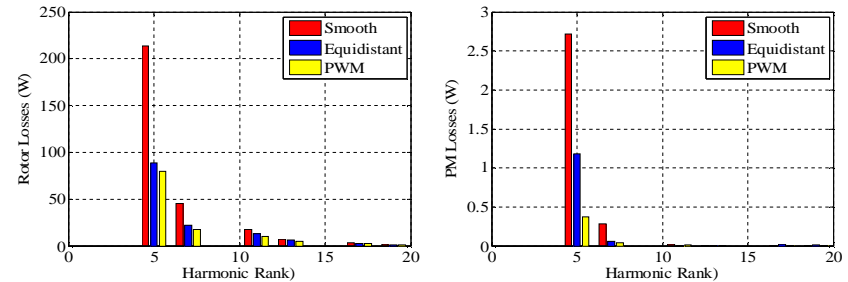

Fig. 7. Eddy Current losses due the armature reaction harmonics..

\section{CONCLUSION}

The rotor losses in Fractional-Slot PM motors are investigated and modeled by using harmonic analysis of the equivalent current density sheet of the stator currents. A method based on PWM grooving of the rotor surface is applied to reduce the rotor losses. In general, the inset PMs are protected by the rotor against the armature reaction and the losses are located mainly in the solid rotor. This situation does not mean that the PMs are protected without rotor grooving or any other technique. The Losses in the rotor increase the temperature of both rotor and PMs by thermal conduction. Therefore, it is necessary to keep the total losses in the rotor as weak as possible to prevent the magnets demagnetization of the magnets.

\section{ACKNOWLEDGMENT}

This work is supported in part by the Commission on Higher Education (CHE), the Thailand Research Fund (TRF) under research grant for new scholars-TRG5680067, the Rajamangala University of Technology Suvarnabhumi, the faculty of engineering and architecture (RMUTSB), THAILAND, and the University of Lorraine, GREEN-Nancy, FRANCE.

\section{REFERENCES}

[1] A.M. El-Refaie, "Fractional-Slot Concentrated-Windings Synchronous Permanent Magnet Machines : Opportunities and Challenges", IEEE Trans. Indust. Electronics, vol. 57, pp. 107-121, Jan. 2010.

[2] W. Jiabin, V. I. Patel, W. Weiya, "Fractional-Slot Permanent Magnet Brushless Machines with Low Space Harmonic Contents", IEEE Trans. Magn., vol. 50, no. 1, Part. 2, January 2014.

[3] A. Qazalbash, S. Sharkh, N. Irenji, R. Wills, M. Abusara, "Rotor Eddy Current Power Loss in Permanent Magnet Synchronous Generators Feeding Uncontrolled Rectifier Loads", IEEE Trans. Magn., in Press 2014.

[4] K. Yamazaki, Y. Fukushima, M. Sato, "Loss Analysis of PermanentMagnet Motors With Concentrated Windings-Variation of Magnet Eddy-Current Loss Due to Stator and Rotor Shapes", IEEE Trans. Indust. App., Vol. 45, no. 4, pp. 1334-1342, 2009

[5] A. Belahcen, A. Arkkio, "Permanent magnets models and losses in 2D FEM simulation of electrical machines ", XIXth Int. Conf. on Electrical Machines (ICEM), pp. 1-6- Roma 2010

[6] P. Arumugam, T. Hamiti, C.A. Gerada, "Estimation of Eddy Current Loss in Semi-Closed Slot Vertical Conductor Permanent Magnet Synchronous Machines Considering Eddy Current Reaction Effect", IEEE Trans. Magn., ., vol. 45, no. 10, October 2013.

[7] A. Cavagnino, A. Miotto, A.Tenconi, S. Vaschetto, "Eddy current losses reduction in fractional slot concentrated winding PM generators for More Electric Engine application", Int. Conf. on Clean Electrical Power (ICCEP), pp. 357-363, 2011

[8] S. Chaithongsuk, N. Takorabet, F. Meibody-Tabar, "On the use of Pulse Width Modulation Method for the elimination of Flux Density Harmonics in the Air-Gap fo Surface PM Motors, "IEEE Trans. Magn. vol. 45, no.3, pp. 1736-1739, march 2009.

[9] M. M. Liwschitz, "Distribution factors and pitch factors of the harmonics of a fractional-slot winding", Transactions of the American Institute of Electrical Engineers, Vol.: 62, no. 10, 664-666, 1943

[10] A. O. Di Tommaso,F. Genduso, R. Miceli, "A software for the evaluation of winding factor harmonic distribution in high efficiency electrical motors and generators", 8th Int. Conf. and Exh. on Ecological Vehicles and Renewable Energies (EVER), 